\title{
O POEMA EM LIBRAS BANDEIRA BRASILEIRA DE NELSON PIMENTA A PARTIR DE UM PONTO DE VISTA FORMAL
}

\author{
THE POEM IN LIBRAS BANDEIRA BRASILEIRA BY NELSON PIMENTA \\ FROM A FORMAL POINT OF VIEW \\ EL POEMA EN LIBRAS BANDEIRA BRASILEÑA POR NELSON PIMENTA \\ DESDE UN PUNTO DE VISTA FORMAL
}

Márcia Maria de Melo Araújo*

\begin{abstract}
Resumo
Este é um estudo sobre a construção formal de alguns versos sinalizados do poema Bandeira brasileira de Nelson Pimenta, destacado ator e poeta surdo brasileiro. Utilizando-se das noções da estrutura fonológica, gesto e dos efeitos da modalidade sobre a linguagem espacial, o estudo pretende verificar a construção do poema em Libras, a partir de um ponto de vista formal. O poema referido destaca-se por uma contextualização crítica da forma e de temas consagrados pela tradição surda brasileira. Peter MacNeilage (2008), Janzen e Shaffer (2002), Quadros e Sutton-Spencer (2006), Karen Emmorey (2002), entre outros autores, contribuíram para o referencial teórico deste ensaio.
\end{abstract}

Palavras-chave: Libras, Modalidade Formal, Nelson Pimenta, poema.

\section{Introdução}

Contextualizar o poema não é simplesmente datá-lo, mas inserir as suas imagens e pensamento em uma trama multidimensional, a partir da qual o eu lírico vive, ora suas experiências, ora lembranças guardadas na memória, ora valores tradicionais, ora crenças e esperanças. Assim, para entender que experiência calcada no sujeito pode suscitar essa e não

\footnotetext{
* Doutora em Estudos Literários pela Universidade Federal de Goiás. Professora da Universidade Estadual de Goiás, onde atua na graduação e no Programa de Pós-Graduação Interdisciplinar em Educação, Linguagem e Tecnologias (PPG-IELT). Líder do Grupo de Estudo e Pesquisa em Literaturas de Língua Portuguesa (GEPELLP). Membro da Associação Brasileira de Estudos Medievais (ABREM) e do GT de Estudos Medievais da Anpoll. E-mail: marcimelo@gmail.com
} 
aquela imagem metafórica tentar-se-á seguir uma concepção renovada de historicidade da prática simbólica para dar conta das imbricações de sujeito e de trama social, mesmo porque o que é chamado genericamente de "sociedade" entra no sujeito na medida em que este se forma e se transforma no drama e na trama das relações com outros sujeitos e consigo mesmo.

Nesse sentido, o presente estudo é uma reflexão sobre a construção formal de alguns versos sinalizados do poema Bandeira brasileira de Nelson Pimenta, destacado ator e poeta surdo brasileiro. Utilizando-se das noções da estrutura fonológica, gesto e dos efeitos da modalidade sobre a linguagem espacial, busca-se mostrar o expediente contextualista e interpretativo da poética surda e dos seus valores temático-culturais utilizado por Nelson Pimenta, especificamente no mencionado poema. Este tem a finalidade de legitimar o modo de ser da cultura surda e a construção da poesia pela experiência sensorial, característica central de muitos poemas nas línguas de sinais, caras à identificação da herança histórica e literária surda.

\section{Estrutura fonológica, gestos e efeitos da modalidade}

Não é de hoje que as mãos sinalizam pensamentos. São Gregório de Nissa (2011), em seu Tratado da criação do homem (379 d.C.), já visualizava certa intuição que associa o gesto à palavra: desenvolvendo as mãos e os instrumentos que estendem o seu uso, os homens puderam exercer com mais eficiência a sua ação sobre o mundo que os cerca. Em posição ereta, com a face distanciada do chão, o homem pôde criar uma nova função para as mãos e codificar sentimentos, sentidos e significados.

Baseados nesse apontamento de São Gregório vários estudiosos e pesquisadores da linguagem formularam teses e enfrentaram questionamentos. Mais recentemente, quando os linguistas se deram conta de que as línguas sinalizadas são também línguas naturais, surgiram os primeiros estudos destinados a identificar e a interpretar se as línguas de sinais compartilham das mesmas propriedades universais das línguas naturais como a produtividade e a arbitrariedade. Entre esses estudos, Peter MacNeilage (2008) deixa claro sua afirmação sobre a existência de uma comunicação feita com as mãos, anterior à fala:

In short, from my point of view, the contention that we had an earlier sign language entails two things: (1) a pre-existing manual phonology enabling 
lexical productivity, and (2) a subsequent implementation of a system of cross-modality equivalences for a hand-to-mouth translation - a system for translation from simultaneous to successive. Arguing that the translation was made before speech took on systematic form characterized by frame structure would seem to be altogether too fanciful. I myself can't find enough evidence that the required system-level equivalences could ever have existed. And McNeill's work suggests that we still have more or less instantaneous holistic gestures - plausible candidates for early gestures - and they coexist with spoken linguistic utterances. My conclusion is that early manual communication did not have a productive phonological level, and it was therefore unnecessary for there to have been a systematic relation between the phonology of signed language and speech enabling translation from one to the other to occur (MACNEILAGE, 2008, p. 288).

Entretanto, o autor assinala que parece haver uma opção perfeitamente plausível que reconhece a verossimilhança de uma longa tradição de uso gestual. Isto implica aceitar e reconhecer o papel atual do gesto tal e qual ocorre com a linguagem imagética como um componente do uso da língua. Em outro estudo, novamente os gestos voltam à tona como elemento indicador de um substrato no processo de gramaticalização de línguas de sinais.

A futher advantage to studying grammaticization in a signed language,
however, may be that it offers a unique look at language change. What are
commonly thought of as "gestures" - that is, nonlinguistic but
communicative gestures of the hands and face - are of the same
neuromuscular substrate as are the linguistic, fully conventionalized signs of
ASL (Armstrong et al. 1995). Several studies have shown that components
of generalized, nonlinguistic gesturing are evident in ASL in the phonetic
inventory (e.g. Janzen 1997), the routinized lexicon (Shaffer 2000), and in
syntactic and morphosyntactic relations (Armstrong et al. 1995). The present
study, however, shows that the role that gesture plays in the development of
grammatical morphemes is also critical, and not opaque when viewed
through the lens of grammaticization principles (JANZEN, SHAFFER,
2002, p. 220).

No estudo de Janzen e Shaffer (2002), os autores indicam evidências que sugerem que os precursores de itens gramaticais na língua de sinais americana são gestos naturais. Além disso, marcadores modais como "future", "can" e "must" assim como "topic marking" tiveram como fonte gestos pré-linguísticos. O que se quer destacar, no momento, é que o estudo dos autores aponta para o papel fundamental que o gesto desempenha no desenvolvimento de morfemas gramaticais, não opaco quando visto através da lente de princípios de gramaticalização. Em outras palavras, trata-se de um processo pelo qual 
determinada palavra passa a ser usada como vocábulo gramatical ou como afixo, no curso da evolução de uma língua.

Nota-se que a linguagem se desenvolve a partir de uma necessidade e presume-se vir daí o alto grau simbólico desenvolvido pelo homem, conforme aponta Ib Ulbaek (1998) em seu trabalho sobre The origin of language and cognition. Entretanto, o que se pretende para este ensaio sobre a construção poética de Bandeira brasileira, um poema interpretado por Nelson Pimenta, destacado ator e poeta surdo brasileiro, é o estudo sobre a construção formal e conteudística de alguns versos sinalizados do mencionado poema.

Contudo, para esta apresentação, não se pretende descobrir instâncias do processo de gramaticalização dos gestos, embora o tema seja de grande importância. Esse é um dos questionamentos linguísticos e determinar porque existe representa um dos objetivos principais da pesquisa da linguística moderna em geral e especificamente da tipologia. Aliás, em toda a probabilidade, a unidade da língua, e os consequentes universais da linguagem, surge de uma interação de fatores, alguns inatos, outros funcionais, e outros ainda cognitivos, experienciais, sociais ou históricos (WHALEY, 1997). O que se pretende ressaltar é a importância desses estudos para compreensão da modalidade e estrutura nas línguas sinalizadas e, em especial, o papel dos gestos e da iconicidade no discurso poético.

“A poesia em língua de sinais, assim como a poesia em qualquer língua, usa uma forma intensificada de linguagem ("sinal arte") para efeito estético" (QUADROS, SUTTONSPENCER, 2006, p. 111). Segundo as estudiosas da linguagem de sinais brasileira, esse tipo de poesia explora os recursos linguísticos para obter efeitos estéticos como, por exemplo, o uso criativo de configurações de mão, movimentos, locações e expressões faciais. Num primeiro plano, a linguagem se apresenta por meio desses recursos, além de trazer sinais já existentes na língua projetados de forma regular. Dessa maneira, a linguagem atinge um significado adicional, apontando para múltiplas interpretações através do movimento e forma, curso e recorrência, sequência e estrutura.

Nessa complexidade está a força e a fraqueza do discurso que se impõe ou se fragiliza pelo efeito do ícone que seduz com a sua pura presença. O discurso dá-se sem tardar à fruição do olho, guardando a transcendência do objeto. A imagem impõe-se. 
Bandeira Brasileira por Nelson Pimenta

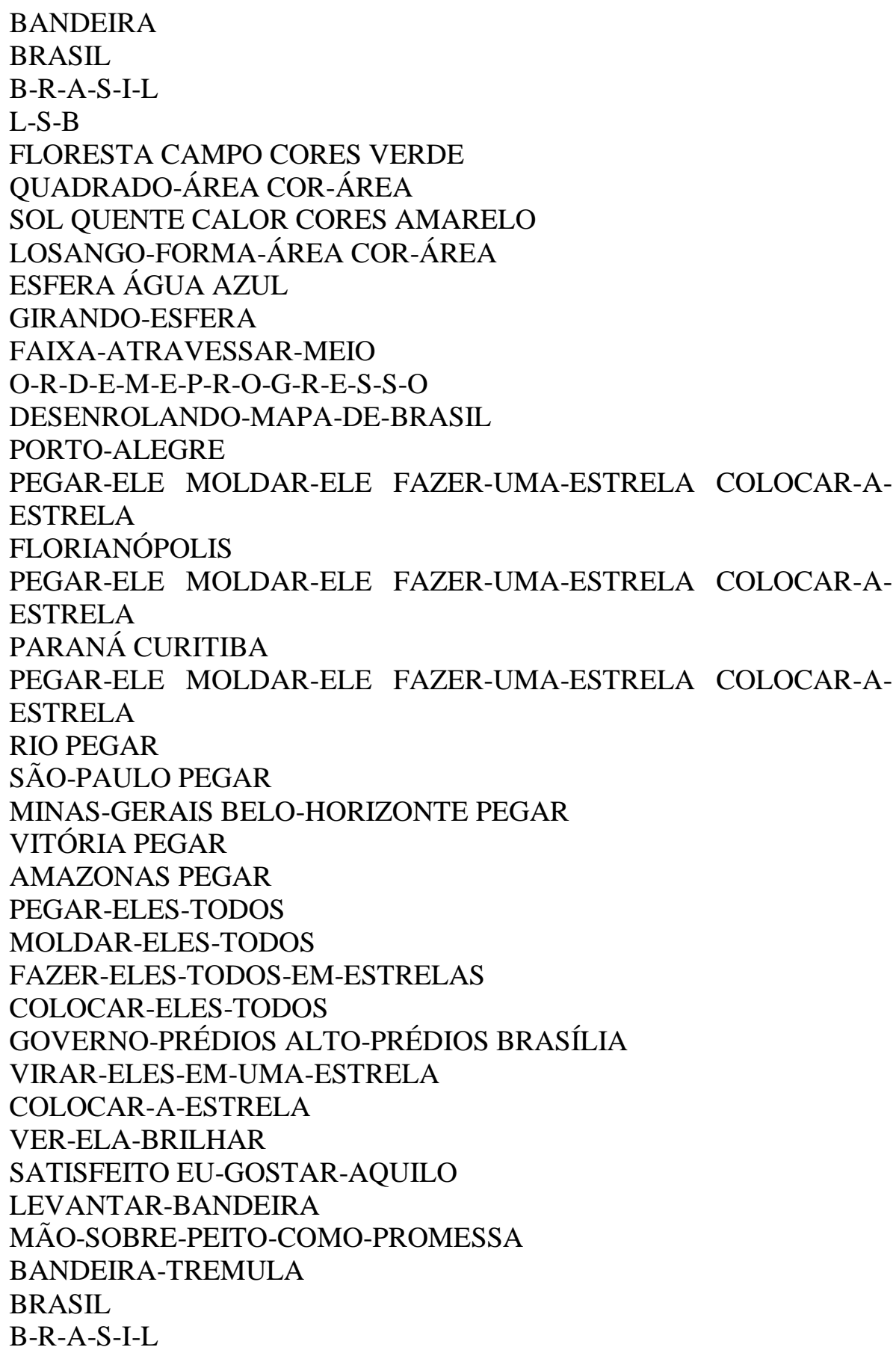

Bandeira Brasileira

Narração interpretada da Língua Brasileira de Sinais:

Há três cores simbólicas: o verde no fundo das florestas e do campo; o losango amarelo que representa o sol e o calor do país; a esfera azul que é 
água. Na faixa que cruza a esfera está escrito: "ordem e progresso". Esboçando um mapa do Brasil, nós temos as estrelas que são representadas na esfera por Porto Alegre; Florianópolis, uma outra estrela; Paraná-Curitiba, mais uma estrela; Rio, São Paulo, Minas Gerais-Belo Horizonte, Vitória, Amazonas; todas capitais (ou estados) têm seus lugares entre as estrelas. Os prédios do governo em Brasília; sim, Brasília, uma outra estrela brilhando. Eu estou satisfeito. Eu gosto disso! Eu levanto a bandeira com respeito. Brasil.

(PIMENTA, 2002).

Diante desse processo, associam-se dois movimentos: a sensação que o objeto é capaz de provocar; no caso, a bandeira brasileira e os significados simbólicos a ela atribuídos, e o sentimento ou sensação interna que o eu lírico transmite. Como numa espécie de acordo subjetivo entre as reações sensoriais e emotivas e o modo de articulação por meio de determinado sinal. Assim, chega-se ao limiar da expressão, que supõe movimentos internos ao corpo. Os signos a que se atribui maior dose de motivação seriam portadores de certas sensações que integram experiências fundamentais do corpo humano, a exemplo de:

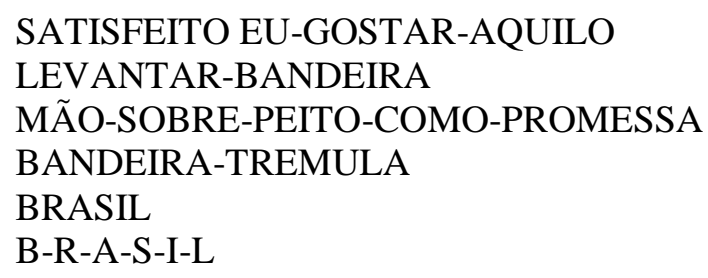

[Eu estou satisfeito. Eu gosto disso! Eu levanto a bandeira com respeito. Brasil.]

(PIMENTA, 2002).

No poema de Nelson Pimenta, a analogia é responsável pelo sabor da imagem que as metáforas e as demais figuras dão ao poema, como, por exemplo, em VIRAR-ELES-EM-UMAESTRELA. Tal uso da imagem supõe claramente que se admite um caráter motivado nos processos semânticos em jogo. Este é um critério válido para acentuar as virtudes miméticas ou expressivas da metáfora, porém se torna discutível por parecer confundir a natureza linguística das figuras com a matéria visual, ou onírica, da imagem. Não se pretende investigar a analogia, aqui, como uma fusão, mas como enriquecimento da percepção.

A rigor, Nelson Pimenta considera importante a forma como a linguagem é usada para produzir o efeito poético. Entretanto, mais do que isso, o autor quer explorar o impacto da poesia e o seu papel na construção da identidade de um povo. Reafirmando o lado positivo da experiência surda da vida e da existência visual dos surdos, a visão participa do primeiro 
plano na mensagem poética. Abre-se aqui um parêntese, para uma alusão a Santo Agostinho que define o olho como o mais espiritual dos sentidos. E por trás dele, todo o platonismo reporta a ideia à visão, pois o olho tem o poder de captar o objeto sem tocá-lo, sem cheirá-lo, sem degustá-lo. Por meio desse órgão, pode-se intuir e compreender sinteticamente a imagem, construindo-a não por assimilação, mas por similitudes e analogias. Daí o fascínio com que o homem procura achegar-se à sua substancialidade. Fecha-se o parêntese.

A respeito da visão como participante em primeiro plano da mensagem poética para o surdo, Quadros e Sutton-Spencer fazem a seguinte observação:

\begin{abstract}
Colocar as imagens do olhar e da visão em poema na língua de sinais fortalece o poeta e a platéia, mostrando sua identidade visual. Há pelo menos três maneiras principais nas quais o poeta pode trazer a experiência visual para o primeiro plano. Primeiramente, o poema pode incluir o uso explícito dos verbos da visão ou fazer a referência direta ao ver ou aos olhos. Os sinais podem ser itens lexicais manuais, em que as mãos representam as atividades dos olhos, ou os sinais podem ser não-manuais, usando a atividade dos olhos diretamente para representá-los. Esse uso dos olhos para representar os próprios olhos é visto também na "caracterização", a segunda maneira em que a experiência visual está em primeiro plano. Nesse recurso, o poema mostra a maneira como os personagens dentro do poema usam os olhos. O uso poético da caracterização é também conhecido como "mudança de papel", "personalização" ou "ação construída" (ver Emmorey, 2003). Antes de 1976, em algumas notas de palestras não publicadas, a poeta pioneira da língua de sinais, Dot Miles, identificou a importância da caracterização (ela usou o termo "personalização") para permitir sinalizantes "transformarem-se" na pessoa ou na coisa da qual estão falando quando sinalizam uma descrição ou uma narrativa direta. (2006, p. 118).
\end{abstract}

As autoras destacam três formas basilares em que o poeta pode se expressar para trazer a experiência visual ao primeiro plano: o uso dos verbos relacionados à visão; as mãos como representação de sinais ou atividades dos olhos, e o uso da personalização ou caracterização. Para este ensaio, evidencia-se a caracterização, recurso que permite ao sinalizante se transformar na pessoa ou coisa sobre a qual está falando.

Em The effects of modality on spatial language: how signers and speakers talk about space, Karen Emmorey (2002) reconhece que a relação entre língua e percepção visual tem uma dimensão adicional para os sinalizadores, pois eles veem o que estão falando sobre. Quer dizer, sinalizadores veem, em vez de ouvir, descrições espaciais e existe um isomorfismo esquemático entre aspectos do sinal linguístico (a localização das mãos no espaço sinalizado) e aspectos da cena espacial descrita (a localização de objetos no espaço descrito). Dessa 
forma, sinalizadores devem integrar um sinal linguístico visualmente observado com um ambiente também visualmente observado ou uma imagem visual de um ambiente descrito.

A leitura de Bandeira brasileira permite essa analogia, cujo núcleo da definição é o conceito dinâmico de transferência. O que significa isso? Significa que as línguas de sinais exprimem informação espacial ao usar construções classificadoras, em que as relações espaciais são expressas pelo local em que as mãos se colocam no espaço da sinalização ou em relação ao corpo.

No caso de Bandeira brasileira, na medida em que o poeta descreve florestas e campos verdes, o sol quente e a água, vai se formando a imagem da bandeira acariciada suavemente pelas mãos do vento. Como em um processo de sobreposição, as imagens ganham contornos e surge um mapeamento esquemático e isomórfico entre a localização das mãos dentro do espaço de sinalização e a localização dos objetos descritos. Nenhuma transformação mental é solicitada ao receptor, de forma que o espaço é compartilhado.

Para Emmorey (2002), o espaço é compartilhado no sentido de que ele é mapeado para o espaço fisicamente observado e para a visão do espaço físico, tanto do sinalizante quanto do receptor. Assim, no poema de Nelson Pimenta, a descrição é feita a partir de um local conhecido por ambos, sinalizante e receptor, ao indicar ao fundo a Bandeira nacional. A referência à bandeira torna-se multidimensional e representacional ao mesmo tempo, pois é ela que ocupa o espaço e direciona o receptor a um encontro com todo território nacional, representado pelas estrelas e respectivamente pelas cidades e estados que significam. Essa referência desempenha na poesia analisada a propriedade de inspirar e de dar forma e modo de ser à atual visão do poético expressa por Nelson Pimenta.

Pimenta professa essa correspondência com um gesto de respeito, expondo, no poema, o propósito geométrico da imagem, a sua dinâmica constelação, iluminando o caráter da representação de fazer a sua poesia enquanto "leitura-construção" (TODOROV, 1975, p. 420), de forma transubstanciada, do seu modelo elegido, sugerindo pelo ritmo e pela repetição o sentimento de brasilidade, em que cada estado se transforma em estrela. Sinaliza Nelson Pimenta:

PORTO-ALEGRE

PEGAR-ELE MOLDAR-ELE FAZER-UMA-ESTRELA COLOCAR-AESTRELA

FLORIANÓPOLIS 


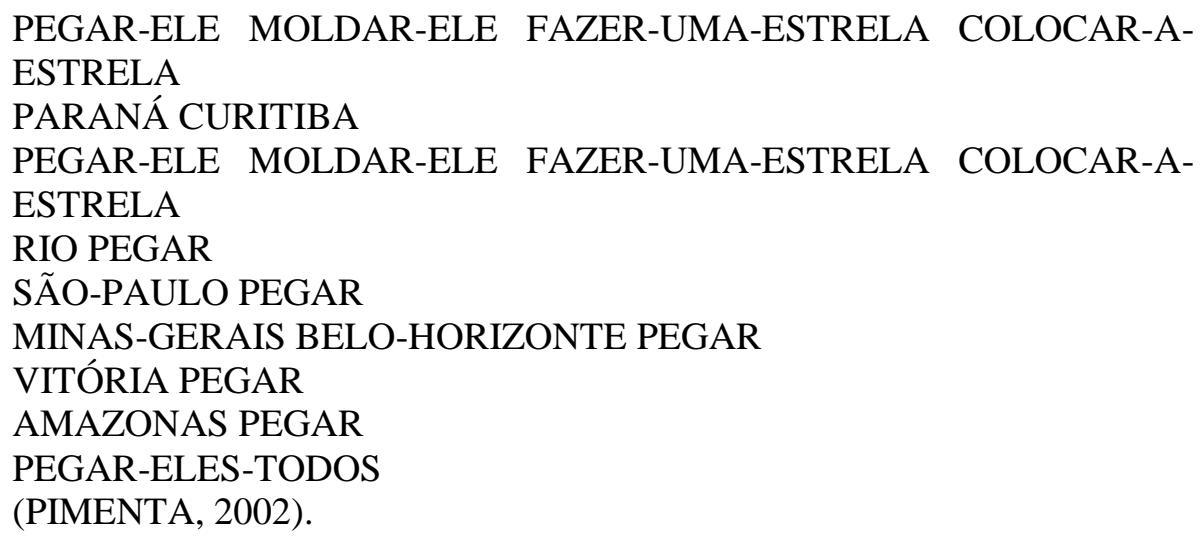

Nota-se a presença da analogia e da repetição. O primeiro constitui uma das maneiras mais usadas pela humanidade para entender ou analisar algo; o segundo causa um efeito de memorização e de tornar algo verossímil e mais próximo do receptor. Além de preservar o valor do seu "próprio poético", utilizando aqui a expressão de Castro (1984), o poema de Nelson Pimenta, com inédita criatividade, mergulha no plano do imaginário, percorrendo o subsolo do Inconsciente, para aferrar o eixo natural de um símbolo poético, que diz respeito ao sentimento de pertencimento a uma nação, tornando-o atual na medida em que avalia e constrói as suas ideias e sentimentos originais (BROWNLEE, 1989).

Assim, pode-se notar que uma imagem no poema não é simplesmente um ícone do objeto que se fixou na retina, mas um código novo, que surge para fixar experiências de coisas, pessoas ou situações, com o fim de presentificar o mundo. Ou seja, a poesia se vale de uma tática toda sua para recortar, adaptar e socializar as percepções e os sentimentos que o homem é capaz de experimentar.

\section{Algumas considerações}

O processo de construção em Bandeira brasileira alude a um princípio de junção das diferentes partes para formar um todo, começando nessa similitude pela semelhança e dependência, segue apresentando também uma contigüidade com a analogia, a justaposição. Essa ambivalência consiste na comunicação entre dois espaços: o da representação pela linguagem e o da experiência na linguagem. Essa ambivalência espacial da expressão linguística em Libras afeta a natureza da compreensão da linguagem, construindo sentidos. 
Numa análise estrutural, só é possível ler o poema como um todo espaço-temporal por causa da forma coesa que recebe o conjunto de significantes, através do jogo de semelhanças e recorrências que se projeta na cadeia das diferenças. As imagens, vindas da experiência e guardadas na memória, dilatam-se e organizam-se, produzindo conjuntos com a articulação dos significantes.

O desejo de ir além de uma análise estrutural para compreender o processo de construção do poema de Nelson Pimenta aponta para o ponto de vista formal. Contudo a poesia é de fato algo divino, como sinaliza Platão, e é necessário um espírito anímico e consciente para presenciá-la e ir além do que os olhos veem. Despegando-se da fala poética, das afinidades por imagem e som, tão comum aos ouvintes, o poema vai concentrando o poder de fixar e de expressar a relação entre homem e mundo. E a poesia transparece em seu modo de ser.

\begin{abstract}
This is a study of the formal construction of some verses of the poem Bandeira brasileira by Nelson Pimenta, famous actor and deaf Brazilian poet. Using the concepts of phonological structure, gesture and the effects of mode of spatial language, the study aims at verifying the construction of the poem in Libras, from a formal point of view. The poem in question stands out for its critical contextualization of form and themes established by Brazilian deaf tradition. Peter MacNeilage (2008), Janzen and Shaffer (2002), Quadros and Sutton-Spencer (2006), Karen Emmorey (2002), among others, contributed to the theoretical framework of this essay.
\end{abstract}

Keywords: Libras, Formal Mode, Nelson Pimenta, poem.

\title{
Resumen
}

Este es un estudio sobre la construcción formal de algunos versos en lengua de señas brasileña del poema de Bandeira brasileira, de Nelson Pimenta, famoso actor y poeta sordo brasileño. Se usan las nociones de estructura fonológica, gesto y efectos de la modalidad sobre el lenguaje espacial. El estudio pretende verificar la construcción del poema en LIBRAS, desde el punto de vista formal. El poema citado se destaca por ser una contextualización crítica de la forma y de temas consagrados por la tradición sorda brasileña. Peter MacNeilage (2008), Janzen e Shaffer (2002), Quadros y Sutton-Spencer (2006), Karen Emmorey (2002), entre otros autores, contribuyeron para el referencial teórico de este ensayo.

Palabras-clave: Libras, el Modo Formal, Nelson Pimenta, poema. 


\section{Referências}

BROWNLEE, Maria Scordilis. The Counterfeit Muse: Ovid, Boccaccio, Juan Flores. 1989. p. 109-127.

CASTRO, E. M. Melo e. A Literatura Portuguesa de Invenção. DIFEL: São Paulo, 1984. p. 5-23, 69-77, 129-166.

EMMOREY, Karen. The effets of modality on spatial language: how signers and speakers talk about space. In: MEIER, Richard P.; CORMIER, Kearsy; QUINTO-POZOS, David. Modality and structure in signed and spoken languages. Cambridge: Cambridge University Press, 2002. p. 405-421.

GREGÓRIO. A Criação do Homem. Trad. Bento Silva Santos. Rev. Iranildo Bezerra Lopes. São Paulo: Paulus, 2011.

JANZEN, Terry; SHAFFER, Barbara. Gesture as the substrate in the process of ASL grammaticization. In: MEIER, Richard P.; CORMIER, Kearsy; QUINTO-POZOS, David. Modality and structure in signed and spoken languages. Cambridge: Cambridge University Press, 2002. p. 199-223.

MACNEILAGE, Peter F. An amodal phonology? Implications of the existence of sign language. In: . The origin of speech. Oxford: Oxfor Niversity Press, 2008. p. 273290.

PIMENTA, Nelson. Bandeira Brasileira. In:

. Literatura em LSB : Poemas, Fábulas e Histórias Infantis. (Produzido em Língua de Sinais Brasileira. LSB Vídeo, 2002..

QUADROS, Ronice Muller; SUTTON- SPENCER, Rachel. Poesia em lingual de sinais: traços da identidade surda. In: QUADROS, Ronice Muller. Estudos surdos I. Petrópolis, RJ: Arara Azul, 2006. p. 109-165 (série pesquisas).

TODOROV, Tzvetan. La lecture comme construction. Poétique 24, 1975, p. 420.

ULBAEK, Ib. The origin of language and cognition. In: HURFORD, James R.; STUDDERTKENNEDY, Michael; KNIGHT, Chris. Approaches to the evolution of language: social and cognitives bases. Cambridge: Cambridge University Press, 1998. p. 30-43.

WHALEY, Lindsay J. Basics of language typology. In: Introduction to typology: the unity and diversity of language. California: Sage, 1997. p. 3-75. 